\title{
Fotovoltaik modüllerin akım-gerilim eğrilerinin simülasyonunda kullanılacak olan yöntemin seçimi
}

\author{
Ali ŞENTÜRK* \\ Muğla Sıtkı Koçman Üniversitesi, Fen Fakültesi, Fizik Bölümü, Kötekli, Muğla. \\ Geliș Tarihi (Recived Date): 31.10 .2017 \\ Kabul Tarihi (Accepted Date): 14.03.2018
}

Özet

Bir fotovoltaik modülün performansını elde edebilmek için, modüle ait aydınlıktaki akım-gerilim ĕgrisinin bilinmesi gereklidir. Bu çalışmada, akım-gerilim ĕgrilerinin simülasyonunda kullanılan üç adet yöntem (analitik, iterasyona ve tamamen modül bilgilerine dayalı) belirlenen ölçütlere göre karşılaştırılmıştır. Bu ölçütler; doğruluk, hesaplama yükü, ilave bilgi/ekipman gerekliliği ve uygulanabilirliktir. Bu karșılaştırma sayesinde fotovoltaik kullanıcılar, hangi simülasyon yönteminin kendileri için daha uygun olacağına karar verebileceklerdir. Elde edilen sonuçlara göre tamamen modül bilgilerine dayalı yöntemler; sundukları yeterli doğruluk, sahip oldukları az hesaplama yükü ve ilave bilgi/ekipmana gerek kalmadan akım-gerilim ĕgrilenin simülasyonunu gerçekleştirdikleri için kullanıcılar açısından en uygulanabilir yöntemlerdir.

Anahtar kelimeler: Fotovoltaik performans, yöntem, akım-gerilim ĕgrisi, simülasyon.

\section{Selection of method used to simulate current-voltage curves of photovoltaic modules}

\begin{abstract}
In order to obtain photovoltaic performance of a photovoltaic module, it is essential to know its illuminated current-voltage curve. In this, study, three methods (analytical, iterative and solely based on datasheet) that used to simulate I-V curve were compared with respect to particular criteria. These criteria are accuracy, calculation burden, necessity of additional information/equipment and feasibility. This comparison will help photovoltaic users to decide which simulation method is more appropriate for them. Obtained results show that to simulate current-voltage curves methods solely based on
\end{abstract}

\footnotetext{
*Ali ŞENTÜRK, alisen@ mu.edu.tr, https://orcid.org/0000-0001-7033-2957
} 
datasheet having quite accuracy, less calculation burden and no additional information/equipment are most feasible according to photovoltaic users.

Keywords: Photovoltaic performance, method, current-voltage curve, simulation.

\section{Giriş}

Artan enerji tüketimi ile birlikte fosil yakıt rezervlerinin azalması, son yıllarda yenilenebilir enerjinin önemini ortaya çıkarmıştır. Güneş enerjisi ya da daha çok bilinen adı ile fotovoltaik enerji kavramı ilk olarak 1970'lerin başında petrol krizi ile gündelik hayata girmiştir. Fotovoltaik; foto kelimesine karşıllk gelen 1şık ve voltaik'e karşılık gelen gerilim kavramlarının bir araya getirilmesidir. Tanımlandığında ise güneşten gelen enerjinin doğrudan olarak elektrik enerjisine dönüştürüldüğü aygıtları (birimleri) ifade etmektedir. Güneş enerjisinin ve uygulamalarının sahip olduğu bazı avantajlar; kaynağının tükenmez olması, çevreye zarar vermemeleri, modüler yapıda olduklarından mevcut kurulu kapasitelerinin arttırılabilir olması, diğer enerji üreten sistemlere göre basit çalışma teknolojilerine sahip olmaları, düşük bakım maliyetlerine sahip olmaları ve doğrudan ihtiyaç duyulan bölgeye kurulabilmeleri dolayısıyla enerji iletim hatlarına ihtiyaç duymamalarıdır [1]. Bunun yanında, süreksiz olmaları, depolama maliyetlerinin yüksek olması ve büyük miktarda enerji elde etme maliyetinin yüksek olması en bilinen dezavantajlarıdır. Bu nedenle, belirlenen bir coğrafi konumda kurulması planlanan fotovoltaik sistemin yatırım maliyetlerine bağlı olarak geri dönüşüm süresinin bilinmesi ekonomik uygulanabilirlik açısından oldukça önemlidir [2].

Fotovoltaik sürecin temel yapı taşı güneş gözesidir (solar cell). Ancak kırılgan yapısından dolayı dış ortam koşullarına dayanıksız olması ve sahip olduğu düşük çıkış gücü sebebiyle-özdeş güneş gözeleri, genellikle elektriksel olarak seri bağlanarak fotovoltaik modül adı verilen mukavemetli yapılar içerisine yerleştirilmektedirler. $\mathrm{Bu}$ nedenle pratik uygulamalar dikkate alındığında, kurulumu yapılacak fotovoltaik sistemin veya örgünün boyutlandırılması fotovoltaik modüllerin sahip oldukları maksimum çıkış gücü değerlerine göre yapılmaktadır.

Bir fotovoltaik modülün fotovoltaik performansı; maksimum çıkış gücü $\left(\mathrm{P}_{\mathrm{M}}\right)$, kısa devre akımı ( $\left.\mathrm{I}_{\mathrm{SC}}\right)$, açık devre gerilimi $\left(\mathrm{V}_{\mathrm{OC}}\right)$, verimlilik $(\eta)$, dolum çarpanı $(\mathrm{FF})$ ve performans oranı (PR) gibi parametreleri kapsamaktadır. Belirli bir ışınım (G) ve modül sıcaklığındaki $\left(\mathrm{T}_{\mathrm{M}}\right)$ fotovoltaik performansını hesaplayabilmek için, modülün o anki akım-gerilim (I-V) eğrisi bilinmelidir. Bir modülün I-V eğrisini ölçebilmek için, genellikle yüksek maliyete sahip olan özel ekipmanlara ve sensörlere ihtiyaç duyulur. Bunun yanında, sahip oldukları yüksek maliyetlerine rağmen, bu tür ekipmanları her zaman temin etmek de mümkün değildir [3]. Bu nedenle, fotovoltaik modüllerin modellenmesi kaçınılmaz bir olgu olarak karşımıza çıkmaktadır. Fotovoltaik modül için elde edilen sonuçlar daha sonrasında fotovoltaik sisteme genişletilerek, fotovoltaik sistemin gerçek çalışma şartları altındaki fotovoltaik performansı hesaplanır ve buna karşılık gelen ekonomik kazanç tahmin edilir (ön görülür). Böylece kurulum maliyeti bilinen bir fotovoltaik örgü veya sistemin, kurulumu yapılacak bölgede ne kadar süre sonra bu maliyeti karşılayacağı hakkında bir öngörü ortaya konulabilir. 
Modüllerin belirli bir ışınım ve modül sıcaklığındaki I-V eğrilerini simüle etmek için bildirilen yöntemleri; analitik, iterasyon ve tamamen modül bilgilerine dayalı yöntemler olarak sınıflandırmak mümkündür. İlk bildirilen analitik yöntemlerde model parametreleri, aydınlıkta ölçülen I-V eğrilerinden elde edilen başlangıç değerlerinden ve ortaya konan analitik yaklaşımlardan hesaplanmaktadır [4-6]. Sonraki analitik yöntemlerde, model parametrelerini hesaplamak için gerekli olan bu başlangıç değerleri; belirli yaklaşımlar altında türetilen ve genellikle kataloglarda verilen elektriksel değerleri kullanan ifadelerden elde edilmektedir [7,8]. Gelişen bilgisayar teknolojisi ile beraber hesaplama hızının artması, iterasyona dayalı yöntemlere olan ilgiyi arttırmıştır. Tipik bir iterasyon yönteminin en büyük artısı, denklemleri çözmek için gerekli olan başlangıç değerlerine ihtiyaç duymamasıdır. İterasyon yöntemlerinde, öncelikli olarak bir model parametresi belirlenir. Seçilen bu parametreye (genellikle seri direnç $R_{S}$ parametresidir), başlangıç değeri sıfır olmak üzere, adım adım belirlenen artış değerleri eklenerek, her defasında diğer model parametreleri hesaplanır ve belirlenen hassasiyet aralığı yakalandığında iterasyon sonlandırılır. Son yıllarda farklı tipteki fotovoltaik kullanıcılara hitap eden tamamen modül kataloglarında sunulan bilgilere dayalı yöntemler rapor edilmiştir. Bu yöntemler, basit kabuller ve analitik olarak elde edilen ifadelerle, iterasyon veya ölçülmüss I-V eğrisine gerek duymadan model parametrelerini hesaplayabilme kabiliyetine sahiptirler [9-11]. Bunun yanında, belirli ücretler karşılığında ticari olarak temin edilebilen paket yazılımlar kullanılarak da model parametrelerini, fotovoltaik modül ve/veya örgülerin elektriksel performanslarını hesaplamak mümkündür. Bu yazılımların bazıları; TRNSYS, PVsyst, INSEL ve PV FChart'tır [12]. Ancak bu yazılımlar için gerekli olan yüksek maliyetli lisans alma zorluğu, bu yazılımların pek tercih edilmemesine neden olmaktadır.

Son yıllarda güneş enerjisine olan ani yönelim ve bu bağlamda ülkelerin değişen teşvik politikaları, araştırmacıların dışında da fotovoltaik tasarımcıların ve daha küçük ölçekli olan son kullanıcı (end-user) sayısının hızlıca artmasına neden olmuştur. Araştırmacılar; yarıiletken fiziği ve/veya fotovoltaik konularında uzman seviyesinde bilgi sahibi olan ve genellikle akademik çalışmalarda bulunan kişileri, fotovoltaik tasarımcılar ise farklı disiplinlerde (makine mühendisliği, elektrik-elektronik mühendisliği vb.) eğitim alan ve fotovoltaik sistemlerin boyutlandırılması, kontrolü ve en iyi şekilde ekonomik maliyet-geri dönüşüm süresini hesaplayan kişileri ifade etmektedir. Son kullanıcılar ise genellikle araştırmacılar veya tasarımcılar kadar bilgi ve ekonomik olanağa sahip olmayan, evsel veya tarımsal ihtiyaçları gidermek için bir veya birkaç fotovoltaik modüle ihtiyacı olan kişileri tanımlamaktadırlar [1]. Bu yüzden seçilen yöntem, sahip olduğu doğruluğun yanında, hesaplama yükü az ve de uygulanabilir olmalıdır. Sonuç olarak, fotovoltaik modül piyasasının büyüdüğü ve son kullanıcılar için bile ulaşılır hale geldiği günümüzde, fotovoltaik performansı hesaplayabilmek için rapor edilen yöntemlerin kullanıcılar açısından anlaşılması oldukça önemlidir.

Bu çalışmada fotovoltaik modüllerin belirli bir ışınım ve modül sıcaklığındaki akımgerilim (I-V) eğrilerini simüle edebilen üç adet (analitik, iterasyon ve tamamen modül bilgilerine dayalı) farklı yöntemin; doğruluk, hesaplama yükü, ilave bilgi/ekipman ihtiyacı ve uygulanabilirlik kriterleri esas alınarak karşıllaştırılması amaçlanmıştır. Seçilen yöntemler için öncelikle referans model parametreleri hesaplanmıştır. Devamında, hesaplanan referans model parametreleri kullanılarak istenilen çalışma şartları için I-V eğrilerinin simülasyonu gerçekleştirilmiştir ve ölçülen I-V eğrileri ile karışlılaştırılmıştır. 


\section{Yöntem}

Bir modülün belirli bir ışınım ve modül sıcaklığındaki I-V eğrisini elde edebilmek (simülasyonunu gerçekleştirebilmek) için rapor edilmiş yöntemlerin tamamına yakını, Şekil 1'de temsili olarak gösterilen işlem adımlarını uygulamaktadır. Seçilen eşdeğer devre modelinin yanında yöntemleri birbirinden ayıran temel fark, referans koşullarındaki model parametrelerinin hesaplanma biçimidir (Şekil 1.'deki koyu bölge). Bu koşullar (STC: Standard Test Conditions); 1şınımın $1000 \mathrm{~W} / \mathrm{m}^{2}\left(\mathrm{G}_{\text {ref }}\right)$, spektral dağılımın AM1,5 (airmass) ve modül sıcaklığının $25^{\circ} \mathrm{C}\left(\mathrm{T}_{\text {ref }}\right)$ olduğu duruma karşılık gelmektedir [13].

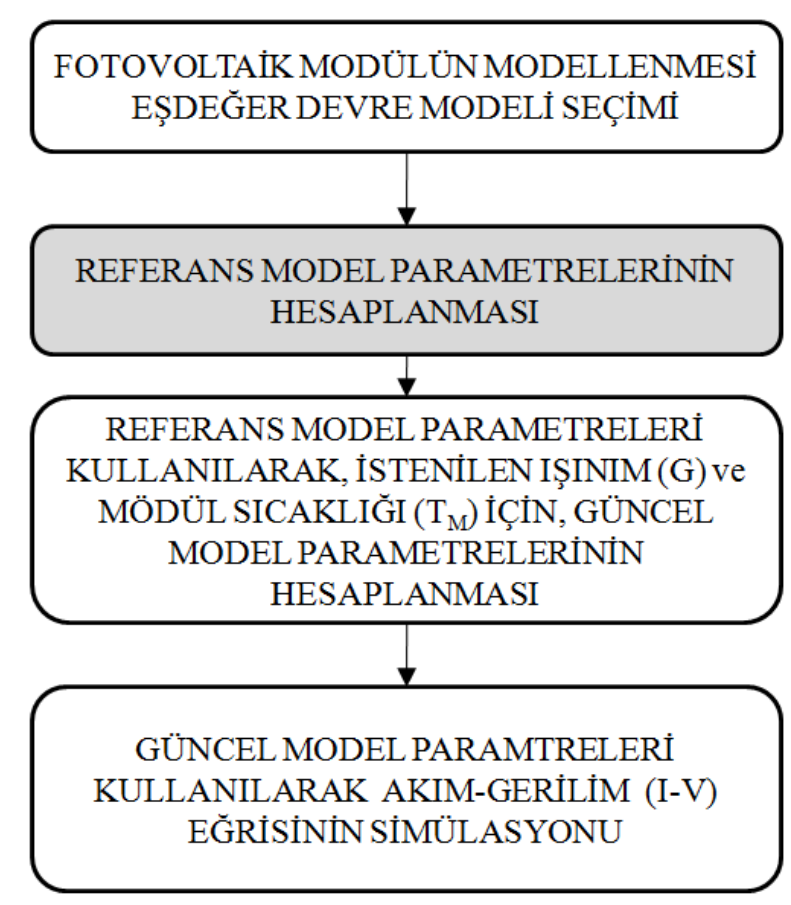

Şekil 1. Temsili olarak akım-gerilim (I-V) eğrilerinin simülasyonu.

Modüllerin I-V eğrilerini simüle etmek için kullanılan en yaygın modeller; tek ve çift diyot eşdeğer devre modelleridir [14,15]. Hesaplama yükü açısından daha karmaşık modeller olmasına rağmen (üçlü diyot) uygulanabilirliklerinin düşük olmasından dolayı pek tercih edilmezler [16]. Çift diyot eşdeğer devre modeli, düşük ışınım değerlerinde veya gölgelendirme durumlarında daha iyi sonuçlar vermesine rağmen, sahip olduğu doğruluk ve hesaplama kolaylığı açısından tek diyot eşdeğer devre modeli hala en çok kullanılan modeldir [17,18]. Bu çalışmada, belirli bir 1şınım ve modül sıcaklığındaki I$\mathrm{V}$ eğrilerinin simülasyonu gerçekleştirmek için seçilen yöntemler tek diyot eşdeğer devre modelinden elde edilmiştir.

Seçilen model için bir sonraki adım, modeli tanımlayan değişkenlerin hesaplanmasıdır. $\mathrm{Bu}$ değişkenler "model parametreleri" olarak adlandırılır. Tek diyot modelinin elektronik eşdeğer devresi; fotovoltaik akımı temsil eden bir akım kaynağı, bu akım kaynağına paralel bağlanmış bir diyot ve bir paralel direnç ile bunlara seri bağlanan bir dirençten meydana gelmektedir (Şekil 2). 


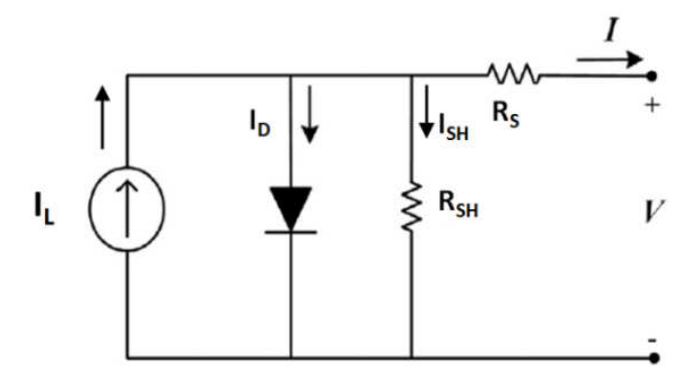

Şekil 2. Tek diyot modelinin elektronik eşdeğer devresi.

Tek diyot eşdeğer devre modelinin genel matematiksel ifadesi aşağıda belirtilmiştir.

$$
I=I_{L}-I_{0}\left(e^{\frac{q\left(V+I R_{S}\right)}{A k_{B} T}}-1\right)-\frac{\left(V+I R_{S}\right)}{R_{S H}}
$$

Burada V; Şekil 2'de artı(+) ve eksi(-) ile gösterilen uçlara bağlanacak olan yük direnci üzerine düşen gerilimi, $\mathrm{I}$; yük direnci üzerinden geçen akımı, q; elektron yükünü ve $\mathrm{k}_{\mathrm{B}}$ ise Boltzmann sabitini ifade etmektedir. Düzeltilmiş diyot faktörünün (A), göze diyot faktörü cinsinden ifadesi aşağıda belirtilmiştir.

$\mathrm{A}=\mathrm{nN}_{\mathrm{S}}$

Burada $\mathrm{n}$; modül içerisindeki tek bir gözenin diyot faktörü ve $\mathrm{N}_{S}$; modül içerisindeki seri bağlanmış göze sayısıdır.

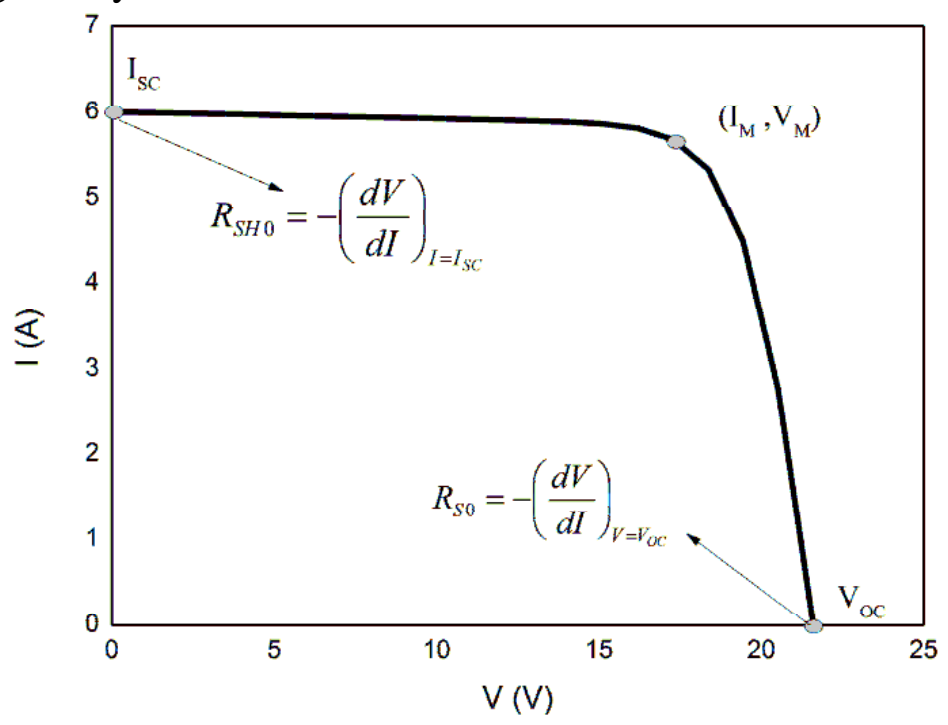

Şekil 3. Belirli noktaların referans akım-gerilim eğrisi üzerindeki konumları.

Tek diyot eşdeğer devre modelini tanımlayan model parametreleri; fotovoltaik akım $\left(\mathrm{I}_{\mathrm{L}}\right)$, karanlıktaki ters doyma akımı $\left(\mathrm{I}_{0}\right)$, düzeltilmiş diyot faktörü $(\mathrm{A})$, seri direnç $\left(\mathrm{R}_{\mathrm{S}}\right)$ ve paralel direnç $\left(\mathrm{R}_{\mathrm{SH}}\right)^{\prime}$ tir [4]. Tek diyot eşdeğer devre modelinin genel ifadesi transandantal yapıda olduğundan, denklemin doğrudan ya da analitik çözümü yoktur $[19,20]$. Bu yüzden, 5 adet parametreyi hesaplayabilmek için en az 5 adet bağımsız denkleme ihtiyaç vardır. Rapor edilen yöntemlerin birçoğu bu 5 adet denklemi, referans I-V eğrisi üzerindeki belirli noktaları kullanarak elde etmektedir [10, 21]. Bu noktalar; 
açık-devre gerilimi $\left(\mathrm{I}=0, \mathrm{~V}=\mathrm{V}_{\mathrm{OC}}\right)$, kısa-devre akımı $\left(\mathrm{I}=\mathrm{I}_{\mathrm{SC}}, \mathrm{V}=0\right)$, maksimum çıkış gücünü sağlayan akım ve gerilim değerleri noktası $\left(I=I_{M}, V=V_{M}\right)$, kısa devre akımı durumundaki türev $\left(\mathrm{R}_{\mathrm{SH} 0}\right)$ ve açık devre gerilimi durumundaki türev $\left(\mathrm{R}_{\mathrm{S} 0}\right)$ olup, bu noktaların referans I-V eğrisi üzerindeki konumları Şekil 3'te gösterilmiştir. Buna rağmen, genel ifadenin transandantal yapısından dolayı, elde edilen denklemler lineer bir çözüm kümesi oluşturmazlar. Bir başka ifade ile bu denklemelerin çözümü birbirlerine bağlıdır. Bu nedenle, sözü edilen 5 adet denklemi çözebilmek için, genellikle belirli başlangıç değerlerine ihtiyaç duyulmaktadır [4, 22].

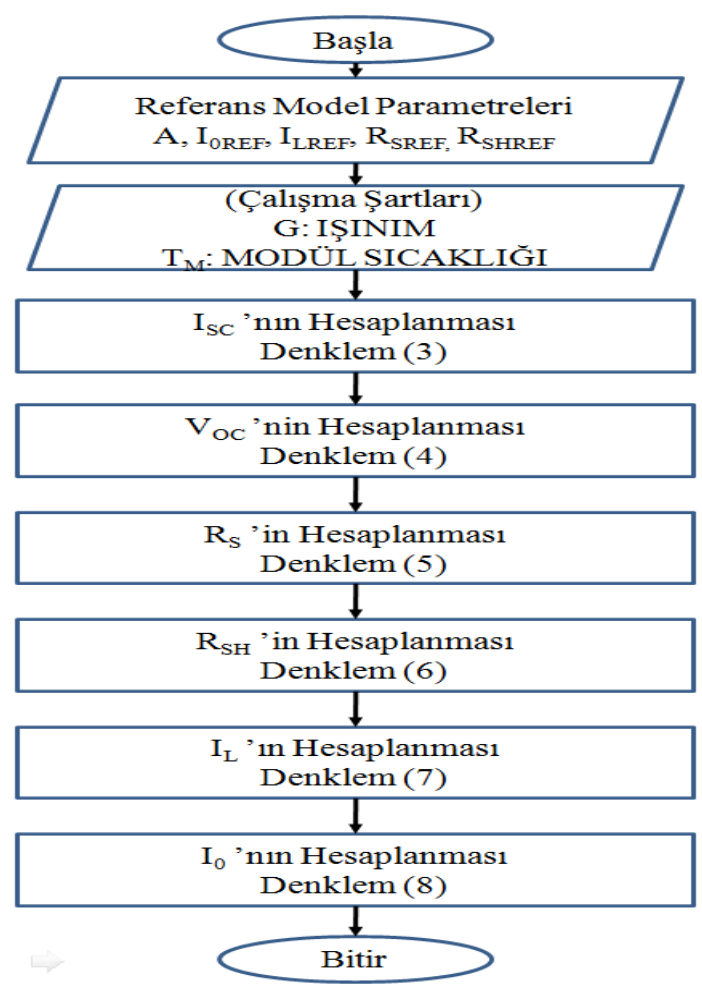

Şekil 4. Güncel model parametrelerinin hesaplanmas1.

Referans model parametrelerinin hesaplanmasından sonra modülün herhangi bir ışınım (G) ve modül sicaklığı $\left(T_{M}\right)$ değerindeki $\mathrm{I}-\mathrm{V}$ eğrisinin simülasyonunu gerçekleştirebilmek için, $G$ ve $T_{M}$ değerleri tarafından belirlenen güncel model parametreleri bilinmelidir. Güncel modül parametreleri $\left(A, R_{S H}, R_{S}, I_{L}\right.$ ve $\left.I_{0}\right)$; referans modül parametreleri ( $\mathrm{A}, \mathrm{R}_{\mathrm{SHREF}}, \mathrm{R}_{\mathrm{SREF}}, \mathrm{I}_{\mathrm{LREF}}$ ve $\mathrm{I}_{0 \mathrm{REF}}$ ) ve aşağıda belirtilen bağıntıların yardımı ile hesaplanmaktadır [11].

$$
\begin{aligned}
& \mathrm{I}_{\mathrm{SC}}=\mathrm{I}_{\mathrm{SCREF}} \frac{\mathrm{G}}{\mathrm{G}_{\mathrm{ref}}}\left(1+\alpha\left(\mathrm{T}_{\mathrm{M}}-\mathrm{T}_{\mathrm{ref}}\right)\right) \\
& \mathrm{V}_{\mathrm{OC}}=\mathrm{V}_{\text {OCREF }}\left(1+\beta\left(\mathrm{T}_{\mathrm{M}}-\mathrm{T}_{\mathrm{REF}}\right)+\frac{\mathrm{Ak}_{\mathrm{B}} \mathrm{T}_{\mathrm{M}}}{\mathrm{V}_{\mathrm{OCREF}} \mathrm{q}} \ln \left(\frac{\mathrm{G}}{\mathrm{G}_{\mathrm{REF}}}\right)\right) \\
& \mathrm{R}_{\mathrm{S}}=\mathrm{R}_{\mathrm{SREF}} \frac{\mathrm{T}_{\mathrm{M}}}{\mathrm{T}_{\mathrm{REF}}}\left(1-0,217 \ln \left(\frac{\mathrm{G}}{\mathrm{G}_{\mathrm{REF}}}\right)\right) \\
& \mathrm{R}_{\mathrm{SH}}=\mathrm{R}_{\text {SHREF }} \frac{\mathrm{G}}{\mathrm{G}_{\mathrm{REF}}}
\end{aligned}
$$




$$
\begin{aligned}
& I_{L}=\left(\frac{R_{S}+R_{S H}}{R_{S H}}\right) I_{S C} \\
& I_{0}=\frac{\frac{\left(R_{S H}+R_{S}\right)}{R_{S H}} I_{S C}-\frac{V_{O C}}{R_{S H}}}{\left(e^{\frac{q V_{O C}}{A k_{B} T_{M}}}-1\right)}
\end{aligned}
$$

Burada $\alpha$ ve $\beta$ ppm $/{ }^{\circ} \mathrm{C}$ (part per million) cinsinden ilgili modülün kısa-devre akımı sıcaklık katsayısına ve açık devre gerilimi sıcaklık katsayısına karşılık gelmektedir. Güncel model parametrelerinin hesaplanması temsili olarak Şekil 4 'te belirtilmiştir.

\section{Seçilen yöntemler}

Bu çalışmada I-V eğrilerinin simülasyonunu gerçekleştirebilmek için; analitik, iterasyon ve tamamen modül bilgilerine dayalı olmak üzere, üç farklı yöntem seçilmiştir. Seçilen yöntemlerin genel tanımları aşağıda özetlenmiştir.

Analitik Yöntem (Y-1): Model parametrelerini hesaplamak rapor edilmiş ilk yöntemdir [4]. Bu yöntem modül kataloglarında sunulan bilgilere ihtiyaç duymadan, farklı 1şınım değerleri altında ölçülmüş bir veya birden fazla $I-V$ eğrilerinin yardımı ile model parametrelerini hesaplayabilmektedir. Model parametreleri, analitik olarak elde edilmiş ve aşağıda gösterilen beş adet ifadenin yardımıyla hesaplanmaktadır.

$$
\begin{aligned}
& \mathrm{A}=\frac{\mathrm{V}_{\mathrm{M}}+\mathrm{I}_{\mathrm{M}} \mathrm{R}_{\mathrm{S} 0}-\mathrm{V}_{\mathrm{OC}}}{\mathrm{V}_{\mathrm{T}}\left\{\ln \left(\mathrm{I}_{\mathrm{SC}}-\frac{\mathrm{V}_{\mathrm{M}}}{\mathrm{R}_{\mathrm{SH} 0}}-\mathrm{I}_{\mathrm{M}}\right)-\ln \left(\mathrm{I}_{\mathrm{SC}}-\frac{\mathrm{V}_{\mathrm{OC}}}{\mathrm{R}_{\mathrm{SH} 0}}\right)+\frac{\mathrm{I}_{\mathrm{M}}}{\mathrm{I}_{\mathrm{SC}}-\left(\mathrm{V}_{\mathrm{OC}} / \mathrm{R}_{\mathrm{SH} 0}\right)}\right\}} \\
& \mathrm{R}_{\mathrm{SH}}=\mathrm{R}_{\mathrm{SH} 0} \\
& \mathrm{I}_{\mathrm{S}}=\left(\mathrm{I}_{\mathrm{SC}} \frac{\mathrm{V}_{\mathrm{OC}}}{\mathrm{R}_{\mathrm{SH} 0}}\right) \exp \left(\frac{-\mathrm{V}_{\mathrm{OC}}}{\mathrm{A} \mathrm{V}_{\mathrm{T}}}\right) \\
& \mathrm{R}_{\mathrm{S}}=\mathrm{R}_{\mathrm{S} 0}-\frac{n \mathrm{~V}_{\mathrm{T}}}{\mathrm{I}_{\mathrm{S}}} \exp \left(\frac{-\mathrm{V}_{\mathrm{OC}}}{\mathrm{AV}}\right) \\
& \mathrm{I}_{\mathrm{L}}=\mathrm{I}_{\mathrm{SC}}\left(1+\frac{\mathrm{R}_{\mathrm{S}}}{\mathrm{R}_{\mathrm{SH}}}\right)+\mathrm{I}_{\mathrm{S}}\left(\exp \left(\frac{\mathrm{I}_{\mathrm{SC}} \mathrm{R}_{\mathrm{S}}}{\mathrm{AV} \mathrm{V}_{\mathrm{T}}}\right)-1\right)
\end{aligned}
$$

İterasyona Dayalı Yöntem $(Y-2)$ : Bu yöntemde model parametreleri, sadece modül kataloglarında verilen bilgilerin ve Şekil 3 'te gösterilen özel noktalar için elde edilen denklemlerin yardımı ile iterasyon tekniği kullanılarak hesaplanmıştır. Kullanılan iterasyon, modül kataloğunda verilen $\mathrm{P}_{\mathrm{MREF}}$ değerinin istenen hassasiyet mertebesinde elde edilmesi ile sonlandırılır [22]. İterasyona dayalı yöntemin hesaplama tekniği temsili olarak Şekil 5 'te gösterilmiștir. Kullanıcı tarafından belirlenen hassasiyet aralığ (ع) ve iterasyon artış değerinin $(\Delta)$ seçimi, iterasyonun ıraksamaması açından oldukça önemlidir. 


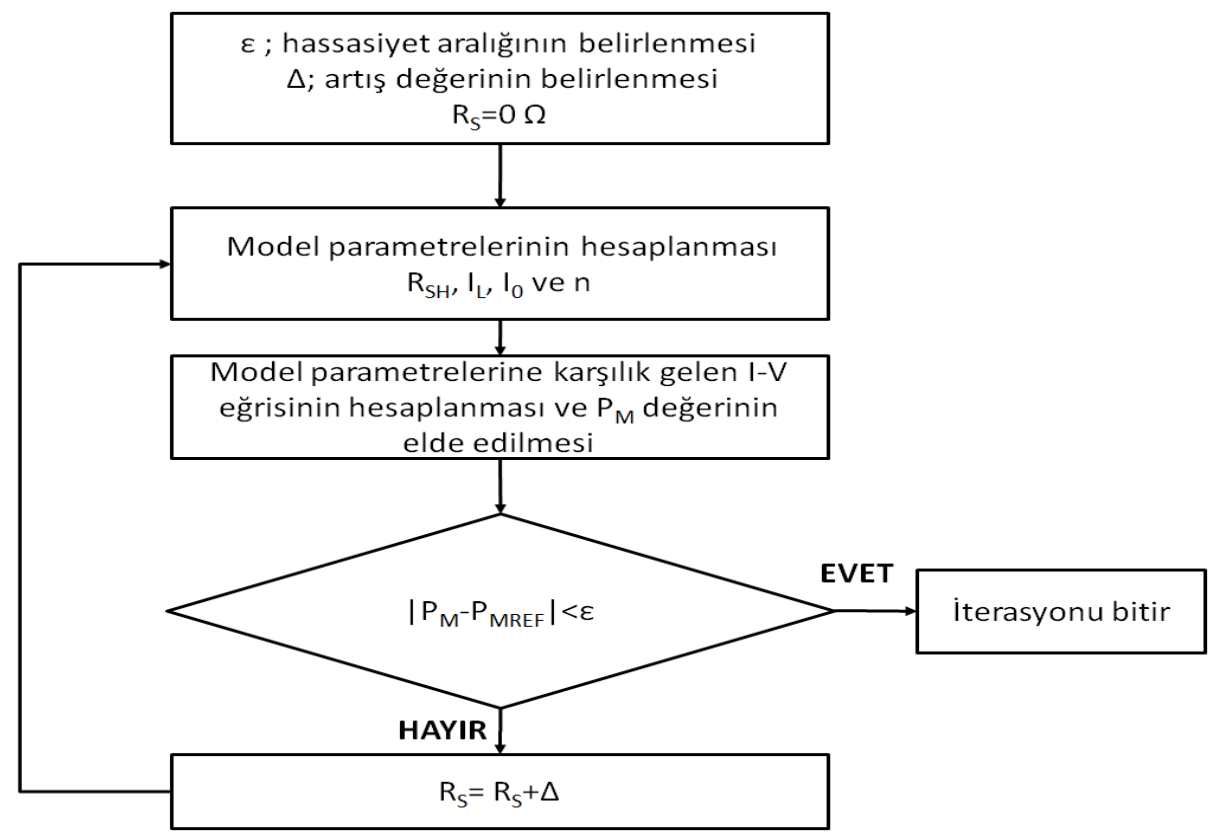

Şekil 5. İterasyona dayalı yöntemlerde model parametrelerini hesaplanması [1].

Tamamen Modül Bilgilerine Dayalı Yöntem (Y-3): Bu yöntem model parametrelerini hesaplamak için sadece modül kataloglarında sunulan bilgilere ihtiyaç duymaktadır. Model parametrelerini hesaplamak için gerekli olan referans koşullarındaki seri direnç ( $\left.\mathrm{R}_{\mathrm{SOREF}}\right)$ ve paralel direnç $\left(\mathrm{R}_{\mathrm{SHOREF}}\right)$ başlangıç değerleri aşağıda belirtilen ifadelerden elde edilmiştir [11].

$$
\begin{aligned}
& \mathrm{R}_{\text {SOREF }}=\frac{\mathrm{V}_{\text {OCREF }}-\mathrm{V}_{\text {MREF }}}{2 \mathrm{I}_{\text {MREF }}} \\
& \mathrm{R}_{\text {SHOREF }}=\frac{\mathrm{V}_{\text {OCREF }}-\mathrm{V}_{\text {MREF }}}{\mathrm{I}_{\text {MREF }}}
\end{aligned}
$$

Bu başlangıç değerlerinin ve aşağıda belirtilen dört adet ifadenin yardımı ile referans model parametreleri, sadece modül kataloglarında sunulan bilgilerden hesaplanmaktadır [11].

$$
\begin{aligned}
& I_{\text {LREF }}=\frac{\left(R_{\text {SREF }}+R_{\text {SHREF }}\right)}{R_{\text {SHREF }}} I_{\text {SCREF }} \\
& I_{\text {OREF }}=\frac{I_{\text {LREF }}-\frac{V_{\text {OCREF }}}{R_{\text {SHREF }}}}{\left(e^{\frac{\mathrm{q}_{\text {OCCFF }}}{\mathrm{Ak} \mathrm{K}_{\mathrm{B}} \text { RFF }}}-1\right)} \\
& \mathrm{R}_{\text {SREF }}=\mathrm{R}_{\mathrm{SOREF}}-\frac{1}{\underline{\mathrm{qV}_{\text {OCREF }}}}
\end{aligned}
$$

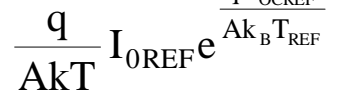




$$
\mathrm{R}_{\text {SHREF }}=\frac{\left(\mathrm{V}_{\text {MREF }}+\mathrm{I}_{\text {MREF }} \mathrm{R}_{\text {SREF }}\right)}{\mathrm{I}_{\text {LREF }}-\mathrm{I}_{\text {MREF }}-\mathrm{I}_{\text {OREF }}\left(\mathrm{e}^{\frac{\mathrm{q}\left(\mathrm{V}_{\text {MREF }}+\mathrm{I}_{\text {MREF }} \mathrm{R}_{\text {SREF }}\right)}{\mathrm{Ak}_{\mathrm{B}} \mathrm{T}_{\text {REF }}}}-1\right)}
$$

\section{Karşılaştırma ölçütleri}

Seçilen yöntemlerin karşılaştırılmasında kullanılan ölçütler aşağıda özetlenmiştir.

Doğruluk (D): Simülasyon sonrasında elde edilen sonuçların, ölçülmüsş (deneysel) sonuçlara olan yakınlığını ifade eden ölçüttür. Simülasyonda kullanılacak olan yöntemin yüksek doğruluğa sahip olması istenmektedir. Bu çalışmada; ölçülen ve simüle edilen I-V eğrilerinin karşılaştırılması, ifade (20) ile gösterilen ortalama karekök yaklaşımı ile gerçekleştirilmiştir [11].

$$
\operatorname{RMSE}(\%)=100 \frac{\sqrt{\mathrm{N} \sum_{\mathrm{I}=1}^{\mathrm{N}}\left(\mathrm{Z}_{\mathrm{CALC}}-\mathrm{Z}_{\mathrm{MEAS}}\right)^{2}}}{\sum_{\mathrm{I}=1}^{\mathrm{N}} \mathrm{Z}_{\text {MEAS }}}
$$

Burada, $Z_{\text {CALC }}, Z_{\text {MEAS }}$ ve $N$ sırası ile hesaplanan değere, ölçülen değere ve veri (ölçüm) sayısına karşılık gelmektedir.

Hesaplama Yükü $(H Y)$ : Model parametrelerini elde edebilmek için gerekli olan hesap yükünü ifade etmektedir.

İlave bilgi/ekipman (IBBE): $\mathrm{Bu}$ kriter model parametrelerini hesaplamak için gerekli olan ve modül kataloglarında kullanıcılara sunulmayan bilgiler ile seçilen yöntemi uygulayabilmek için gerekli olan ilave ölçüm cihazlarını ifade etmektedir.

Uygulanabilirlik $(U): \mathrm{Bu}$ ölçüt seçilen yöntemin; doğruluk, ilave bilgi/ekipman ve hesaplama yükü ölçütlerine göre en dengeli (optimize) şekilde kullanıcılara sunulmasını ifade etmektedir. Örneğin, doğruluğu yüksek olmasına rağmen ilave bilgi ve/veya aşırı hesaplama yüküne sahip yöntemlerin uygulanabilirlik ölçütü "düşük olarak değerlendirilir.

\section{Seçilen yöntemlerin değerlendirilmesi}

Yöntem-1 ve Yöntem-3'te referans model parametreleri analitik olarak elde edilen ifadelerden doğrudan ve basitçe hesaplanmaktadır. Dolayısıyla her iki yöntemin "az" hesaplama yüküne sahip oldukları anlaşılmaktadır. Yöntem-2'de ise, referans model parametrelerini hesaplayabilmek için, iterasyonun yakınsamasını ve hesaplama süresini belirleyen iterasyon artış adamının $(\Delta)$ ve hassasiyet aralığının $(\varepsilon)$ kullanıcılar tarafından belirlenmesi gereklidir. $\mathrm{Bu}$ iki parametrenin seçimi oldukça önemlidir. Yanlış seçim durumunda iterasyon ıraksamakta ve yöntem model parametrelerini hesaplamakta başarısız olmaktadır. Araştırmacılar açısından bu iki parametrenin seçimi iyi bir şekilde gerçekleştirilirken, diğer kullanıcılar için bu seçim oldukça zordur. Bu bağlamda Yöntem-2'in hesaplama yükü " fazla" olarak değerlendirilmiştir 
Yöntem-1'de model parametrelerini hesaplayabilmek için gerekli olan I-V eğrisini elde edebilmek için özel olarak tasarlanmış ölçüm cihazlarına ihtiyaç duyulmaktadır. Benzer olarak Yöntem-2'de ise, iterasyon sürecinin rraksamadan sonuç verebilmesi için artış adımının ve hassasiyet aralığının seçimi ilave bilgi gerektiren bir süreç olarak ortaya çıkmaktadır. Bunun yanında, Yöntem-3'te ise referans model parametrelerini hesaplayabilmek için ilave bilgiye veya ölçüm cihazlarına gerek yoktur, sadece modül kataloglarında kullanıcılara sunulan bilgiler yeterlidir.

Seçilen yöntemlerin simülasyon doğruluklarının test edilmesi amacıyla, KC200GT modülünün farkı çalışma şartlarında ölçülen I-V eğrileri kullanılmıştır. Ölçülen I-V eğrileri Shongwe ve arkadaşlarının rapor ettiği çalışmadan alınmıştır [23]. KC200GT modülünün kataloğunda sunulan ve referans model parametrelerinin hesaplanması için gerekli olan bilgiler Tablo 1'de verilmiştir. Burada, $\mathrm{I}_{\mathrm{MREF}} \quad$ ve $\mathrm{V}_{\mathrm{MREF}} \quad$ sıras1 ile referans koşullarındaki maksimum çıkış gücünün olduğu akım ve gerilimi, $\mathrm{I}_{\mathrm{SCREF}}$ ve $\mathrm{V}_{\text {OCREF }}$ ise referans koşullarındaki kısa devre akımı ve açık devre gerilimini ifade etmektedirler.

Tablo 1. KC200GT modülünün katalog değerleri.

\begin{tabular}{cc}
\hline Parametre & Değer \\
\hline $\mathrm{N}_{\mathrm{S}}$ & 54 \\
$\mathrm{I}_{\mathrm{SCREF}}(\mathrm{A})$ & 8.21 \\
$\mathrm{~V}_{\mathrm{OCREF}}(\mathrm{V})$ & 32.90 \\
$\mathrm{I}_{\mathrm{MREF}}(\mathrm{A})$ & 7.61 \\
$\mathrm{~V}_{\mathrm{MREF}}(\mathrm{V})$ & 26.30 \\
$\alpha\left(\mathrm{ppm} /{ }^{\circ} \mathrm{C}\right)$ & 378 \\
$\beta\left(\mathrm{ppm} /{ }^{\circ} \mathrm{C}\right)$ & -3783
\end{tabular}

Burada, $I_{M R E F}$ ve $V_{\text {MREF }}$ sırası ile referans koşullarındaki maksimum çıkış gücünün olduğu akım ve gerilimi, $\mathrm{I}_{\mathrm{SCREF}}$ ve $\mathrm{V}_{\mathrm{OCREF}}$ ise referans koşullarındaki kısa devre akımı ve açık devre gerilimini ifade etmektedirler.

Seçilen yöntemler kullanılarak hesaplanan referans model parametreleri Tablo 2'de gösterilmiştir.

Tablo 2. Seçilen yöntemler için hesaplanan referans model parametreleri.

\begin{tabular}{cccc}
\hline Model Parametreleri & $\begin{array}{c}\text { Yöntem-1 } \\
{[4]}\end{array}$ & $\begin{array}{c}\text { Yöntem-2 } \\
{[22]}\end{array}$ & $\begin{array}{c}\text { Yöntem-3 } \\
{[11]}\end{array}$ \\
\hline $\mathrm{A}$ & 50.8 & 70.2 & 64.8 \\
$\mathrm{I}_{\text {OREF }}(\mathrm{A})$ & $8.98 \times 10^{-11}$ & $9.83 \times 10^{-08}$ & $5.62 \times 10^{-08}$ \\
$\mathrm{I}_{\text {PHREF }}(\mathrm{A})$ & 8.230 & 8.214 & 8.290 \\
$\mathrm{R}_{\text {SREF }}(\Omega)$ & 0.365 & 0.221 & 0.200 \\
$\mathrm{R}_{\text {SHREF }}(\Omega)$ & 151.5 & 415.0 & 106.8 \\
\hline
\end{tabular}

Seçilen üç yöntem için farklı çalışma koşullarındaki güncel model parametreleri ve bunlara karşılık gelen I-V eğrilerinin simülasyonu Şekil 4'e göre gerçekleştirilmiş ve ölçülen eğrilerle karşılaştırılmıştır. Sabit ışınım farkı modül sıcaklıklarındaki I-V eğrileri Şekil 6'da, sabit modül sıcaklığı farklı 1şınım değerlerindeki I-V eğrileri ise Şekil 7'de gösterilmiştir. 


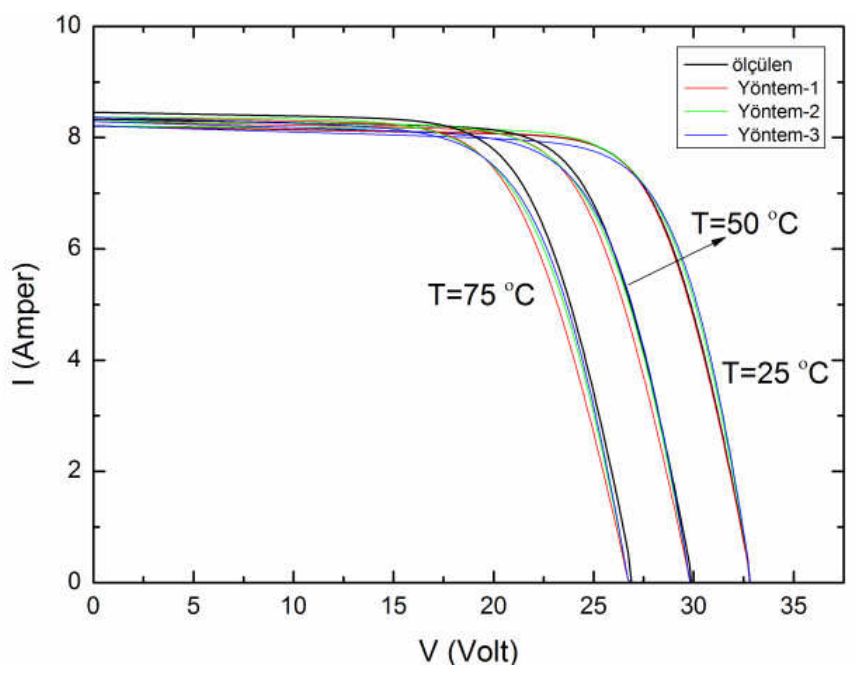

Şekil 6. Farklı modül sıcaklıkları için ölçülen ve simülasyonu gerçekleştirilen I-V eğrileri.

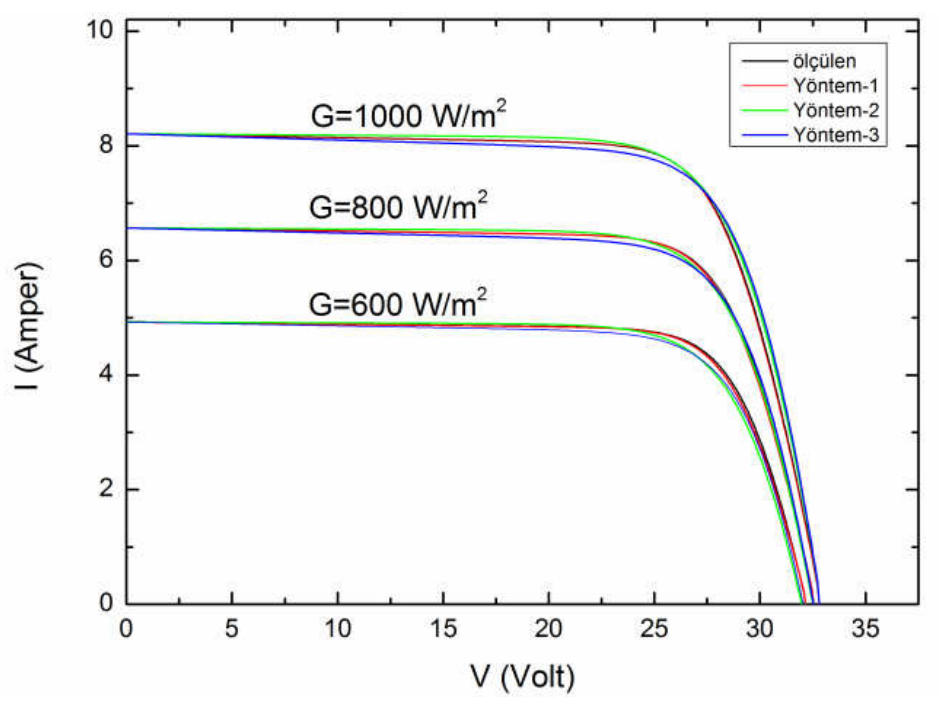

Şekil 7. Farklı 1şınım değerleri için ölçülen ve simülasyonu gerçekleştirilen I-V eğrileri.

Simülasyonu gerçekleştirilen I-V eğrileri için hata değerleri hesaplanmış ve Tablo 3 ve Tablo 4'te gösterilmiştir. Farkı çalışma koşulları için elde edilen hata değerlerinin ortalaması hesaplanmış ve aynı tablolarda gösterilmiştir.

Tablo 3. Seçilen yöntemlerin farklı modül sıcaklığındaki simülasyon hataları.

\begin{tabular}{|c|c|c|c|c|}
\hline $\begin{array}{c}\mathrm{T}_{\mathrm{M}} \\
\left({ }^{\circ} \mathrm{C}\right) \\
\end{array}$ & & $\begin{array}{l}\mathrm{Y}-1 \\
(\%)\end{array}$ & $\begin{array}{l}\text { Y-2 } \\
(\%)\end{array}$ & $\begin{array}{l}\mathrm{Y}-3 \\
(\%) \\
\end{array}$ \\
\hline 25 & & 0.3 & 1.3 & 1.8 \\
\hline 50 & & 2.1 & 0.9 & 1.4 \\
\hline \multirow[t]{2}{*}{75} & & 3.6 & 2.4 & 2.4 \\
\hline & Ortalama Hata & 2.0 & 1.5 & 1.9 \\
\hline
\end{tabular}

Doğruluk ölçütünün belirtildiği Tablo 3 ve Tablo 4 dikkate alındığında, seçilen tüm yöntemler için elde edilen hata değerleri arasında belirgin bir farkın olmadı̆̆ 
anlaşılmıştır. Ayrıca tüm yöntemler için elde edilen ortalama hata değerleri, I-V eğrilerinin simülasyonu için bildirilen hata değeri olan \%4.0'ün altında kalmaktadır [24]. Farklı modül sıcaklıkları için en iyi simülasyonu \%1.5'luk ortalama hata ile Yöntem-2 sağlarken, farklı 1şınım değerleri için bu yöntem \%0.5'lik hata ile Yöntem1'dir.

Tablo 4. Seçilen yöntemlerin farklı ışınımlardaki simülasyon hataları.

\begin{tabular}{|c|c|c|c|c|}
\hline $\mathrm{G}\left(\mathrm{W} / \mathrm{m}^{2}\right)$ & & $\begin{array}{l}\mathrm{Y}-1 \\
(\%)\end{array}$ & $\begin{array}{l}\mathrm{Y}-2 \\
(\%) \\
\end{array}$ & $\begin{array}{l}\text { Y-3 } \\
(\%)\end{array}$ \\
\hline 1000 & & 0.3 & 1.3 & 1.8 \\
\hline 800 & & 0.6 & 0.9 & 1.1 \\
\hline \multirow[t]{2}{*}{600} & & 0.7 & 2.9 & 2.2 \\
\hline & Ortalama Hata & 0.5 & 1.8 & 1.7 \\
\hline
\end{tabular}

Bundan önceki üç ölçüt (doğruluk, hesaplama yükü ve ilave bilgi/ekipman) için yapılan değerlendirmeler dikkate alındığında, Yöntem-1 ve Yöntem-2'nin sahip olduğu simülasyon doğruluğunun daha iyi olmasına rağmen, ilave bilgi/ekipmana ve fazla hesaplama yüküne ihtiyaç duymamasından dolayı, Yöntem-3'ün diğer yöntemler olan Yöntem-1 ve Yöntem-2'ye göre daha uygulanabilir olduğu belirlenmiştir.

\section{Sonuç}

Son yıllarda fotovoltaik enerjiye olan ani yönelim; araştırmacılar, fotovoltaik tasarımcılar ve son kullanıcı olmak üzere farklı tipteki fotovoltaik kullanıcıların ortaya çıkmasına neden olmuştur. Fotovoltaik modüllerin belirli bir 1şınım ve modül sıcaklığındaki I-V eğrisinin simülasyonu için gerekli olan yöntemin seçimini belirleyen en önemli etken fotovoltaik kullanıcılardır. Bu bağlamda kullanıcılara, I-V eğrilerinin simülasyonunu gerçekleştirmek için hangi yöntemin seçilmesi gerektiğinin anlatılması oldukça önemlidir. Bu çalışmada, fotovoltaik modüllerin belirli bir ışınım ve modül sıcaklığındaki I-V eğrilerini simüle edebilen üç adet farklı yöntem; doğruluk, ilave/bilgi ekipman, hesaplama yükü ve uygulanabilirlik ölçütlerine göre değerlendirilmiş ve karşılaştırılmıştır. Elde edilen sonuçlar şu şekilde sıralanabilir. Doğruluk ölçütü dikkate alındığında, seçilen yöntemler arasında belirgin bir fark yoktur. Bir başka ifade ile seçilen tüm yöntemler, I-V eğrisinin simülasyonunu iyi ve kabul edilebilir bir doğrulukla (<\%4.0, Tablo 3 ve Tablo 4) gerçekleştirebilmektedir. Araştırmacılar seçilen tüm yöntemleri kolaylıkla uygulayabilmektedirler. Bunun yanında, diğer yöntemlere nazaran sahip olduğu simülasyon doğruluğu az olsa da, ilave bilgi/maliyet ve hesaplama yükü gerektirmeyen yöntemler daha uygulanabilir olduklarından, özellikle fotovoltaik tasarımcılar ve son kullanıcılar tarafından daha çok tercih edilebilme potansiyeline sahiptirler.

\section{Kaynaklar}

[1] Şentürk, A., Yeni Bir Yöntem İle Kristal Silisyum Tabanlı Fotovoltaik Modüllerin Elektriksel Performansının Hesaplanması Ve Sıcaklık Katsayılarının (İç Ve Dış) Performansa Olan Etkisinin İncelenmesi, Doktora Tezi, Muğla Sıtkı Kocman Universitesi, Fen Bilimleri Enstitüsü,Muğla, (2016). 
[2] Devabhaktuni, V., Alam, M., Depuru, S.S.S.R., Green, R.C., Nims, D. ve Near, C., Solar energy: Trends and enabling technologies, Renewable and Sustainable Energy Reviews, 19, 555-564, (2013).

[3] Averbukh, M., Lineykin, S. ve Kuperman, A., Obtaining small photovoltaic array operational curves for arbitrary cell temperatures and solar irradiation densities from standard conditions data, Progress in Photovoltaics Research and Application, 21, 1016-1024, (2012).

[4] Phang, J.C.H., Chan, D.S.H. ve Phillips, J.R., Accurate analytical method for the extraction of solar cell model parameters, Electronics Letters, 20, 406-408, (1984).

[5] Chan, D.S.H. ve Phangd, J.C.H., Analytical Methods for the Extraction of SolarCell Single- and Double-Diode Model Parameters from I-V Characteristics, IEEE Transactions on Electron Devices, 34, 286-293, (1987).

[6] Jia, Q.X., Ebihara, K. ve Ikegami, T., Analytical solution for solar cell model parameters from illuminated current-voltage characteristics, Philosophical Magazine Part B, 72, 375-382, (1995).

[7] Siddiqui, M.U., Arif, A.F.M., Bilton, A.M., Dubowsky, S. ve Elshafei, M., An improved electric circuit model for photovoltaic modules based on sensitivity analysis, Solar Energy, 90, 29-42, (2013).

[8] Cubas, J., Pindado, S. ve Victoria, M., On the analytical approach for modeling photovoltaic systems behavior, Journal of Power Sources, 247, 467-474, (2014).

[9] Orioli, A. ve Di Gangi, A., A procedure to calculate the five-parameter model of crystalline silicon photovoltaic modules on the basis of the tabular performance data, Applied Energy, 102, 1160-1177, (2013).

[10] Batzelis, E.I. ve Papathanassiou, S.A., A Method for the Analytical Extraction of the Single-Diode PV Model Parameters, IEEE Transactions on Sustainable Energy, 7, (2015).

[11] Senturk, A. ve Eke, R., A new method to simulate photovoltaic performance of crystalline silicon photovoltaic modules based on datasheet values, Renewable Energy, 103, 58-69, (2017).

[12] Lalwani, M., Kothari, D.P. ve Singh, M., Investigation of Solar Photovoltaic Simulation Softwares, International Journal of Applied Engineering Research, 1(3), 585-601, (2010).

[13] Sharma, V., Kumar, A., Sastry, O.S. ve Chandel, S.S., Performance assessment of different solar photovoltaic technologies under similar outdoor conditions, Energy, 58, 511-518, (2013).

[14] Shockley, W., The Theory of p-n Junctions in Semiconductors and p-n Junction Transistors, Bell Labs Technical Lournal, 28, 435-489, (1949).

[15] Gow, J. A. ve Manning, C.D., Development of a photovoltaic array model for use in power-electronics simulation studies, IEEE Proceedings - Electric Power Applications, 146(2), 193-200, (1999).

[16] Khanna, V., Das, B.K., Bisht, D. ve Singh, P.K., A three diode model for industrial solar cells and estimation of solar cell parameters using PSO algorithm, Renewable Energy, 78, 105-113, (2015).

[17] Ma, T., Yang, H. ve Lu, L., Solar photovoltaic system modeling and performance prediction, Renewable and Sustainable Energy Reviews, 36, 304315, (2014).

[18] Elbaset, A.A., Ali, H. ve Sattar, M.A., Novel seven-parameter model for photovoltaic modules, Solar Energy Materials and Solar Cells, 130, 442-455, 
(2014).

[19] Jung, J.-H. ve Ahmed, S., Real-time simulation model development of single crystalline photovoltaic panels using fast computation methods, Solar Energy, 86, 1826-1837, (2012).

[20] Chen, Y., Wang, X., Li, D., Hong, R., Shen, H., Parameters extraction from commercial solar cells I-V characteristics and shunt analysis, Applied Energy, 88, 2239-2244, (2011).

[21] Ciulla, G., Lo Brano, V., Di Dio, V. ve Cipriani, G., A comparison of different one-diode models for the representation of I-V characteristic of a PV cell, Renewable and Sustainable Energy Reviews, 32, 684-696, (2014).

[22] Villalva, M.G., Gazoli, J.R. ve Filho, E.R., Comprehensive Approach to Modeling and Simulation of Photovoltaic Arrays, IEEE Transactions on Power Electronics, 24(5), 1198-1208, (2009).

[23] Shongwe, S. ve Hanif, M., Comparative Analysis of Different Single-Diode PV Modeling Methods, IEEE Journal of Photovoltaics, 5, 938-946, (2015).

[24] Humada, A.M., Hojabri, M., Mekhilef, S. ve Hamada, H.M., Solar cell parameters extraction based on single and double-diode models: A review, Renewable and Sustainable Energy Reviews, 56, 494-509, (2016). 